\title{
Estudo da Expressão Imuno-Histoquímica da $\beta$-Catenina e Wnt-5a em Displasias Epiteliais Bucais
}

Immunohistochemical Study of $\beta$-Catenin and wnt-5a Expression in Oral Epithelial Dysplasias

Estudio de la Expresión Inmunohistoquímica de $\beta$-Catenina y Wnt-5a en la Displasia Epitelial Oral

\author{
Allan Ulisses Carvalho de Melo', Marize Raquel Diniz da Rosa², Luciana Maria Pedreira Ramalho ${ }^{3}$
}

\section{Resumo}

Introduçáo: Expressôes diferenciadas da $\beta$-catenina e Wnt em carcinoma bucal levantam hipóteses sobre seu papel em lesóes cancerizáveis. Objetivo: Avaliar a expressão imuno-histoquímica da $\beta$-catenina e Wnt-5a em displasias epiteliais bucais. Metodologia: Foram analisados cinco casos de tecido bucal normal e 18 de displasia epitelial ( 7 de palato, 3 de mucosa, 6 de gengiva e 2 de lábio). O grau de displasia foi determinado através de coloração HE, obedecendo critérios da OMS. As lâminas foram processadas pela técnica da streptavidina-biotina-peroxidase para a marcação do anticorpo monoclonal. A expressão foi avaliada de acordo com a localização (membranoso, citoplasmático e/ou nuclear) e o índice de marcação por intensidade (ausente, fraca, moderada e forte). Foi realizada análise descritiva sem uso de testes estatísticos. Resultados: Houve 13 casos de displasia leve $(72,2 \%)$ e cinco de moderada $(27,8 \%)$. Quanto à $\beta$-catenina, nas displasias leves $(\mathrm{n}=13)$ foram verificados padróes membranoso $(\mathrm{n}=12)$, citoplasmático $(\mathrm{n}=10)$ e nuclear $(\mathrm{n}=03)$. Nas displasias moderadas $(\mathrm{n}=05)$, perceberam-se os padróes membranoso $(\mathrm{n}=05)$, citoplasmático $(\mathrm{n}=03)$ e nuclear $(\mathrm{n}=01)$. A expressão da Wnt-5a foi negativa em quatro amostras de tecido normal e noutra observouse padrão citoplasmático. Nas displasias leves e moderadas, não houve expressão membranosa da Wnt-5a. Os padrôes exclusivamente citoplasmático $(\mathrm{n}=6 ; 33,3 \%)$ e citoplasmático/nuclear $(\mathrm{n}=7 ; 38,8 \%)$ também foram observados. Conclusão: A marcação citoplasmática e nuclear da $\beta$-catenina e o aumento da expressão da Wnt-5a nas displasias epiteliais bucais diferiram significativamente do padrão da mucosa normal. Não foi possível verificar a relação entre graduação histológica da displasia epitelial bucal e expressão da $\beta$-catenina ou Wnt-5a.

Palavras-chave: Neoplasias Bucais; Imuno-histoquímica

\footnotetext{
${ }^{1}$ Autor. Professor Doutor Titular da disciplina de Estomatologia da Universidade Tiradentes (UNIT-SE).

${ }^{2}$ Orientadora. Professora Doutora Associada do Departamento de Clínica e Odontologia Social da Universidade Federal da Paraíba.

${ }^{3}$ Orientadora. Professora Doutora do Programa de Pós-graduação em Odontologia UFPB/UFBA.

Tese apresentada ao Programa Integrado de Pós-Graduação em Odontologia UFPB/UFBA para obtenção do Título de Doutor em Odontologia, João Pessoa (PB), 2008. Área de Concentração: Estomatologia.

Agência de Fomento: Coordenação de Aperfeiçoamento de Pessoal de Nível Superior (CAPES).

Endereço para correspondência: Allan Ulisses Carvalho de Melo. Av. Acrísio Cruz, 147. Apt. 401. Salgado Filho. Aracaju (SE), Brasil. CEP: 49.020-

210, Brasil. E-mail: aucmelo@yahoo.com.br.
} 